\title{
Astragalus (Astragalus membranaceus Bunge): botanical, geographical, and historical aspects to pharmaceutical components and beneficial role
}

\author{
Alessandra Durazzo ${ }^{1}$ - Amirhossein Nazhand ${ }^{2}$ - Massimo Lucarini ${ }^{1}$. Amelia M. Silva ${ }^{3,4}$. Selma B. Souto ${ }^{5}$. \\ Fabrizia Guerra $^{6}$. Patricia Severino ${ }^{7,8,9} \cdot$ Massimo Zaccardelli $^{10}$ - Eliana B. Souto ${ }^{11,12} \cdot$ Antonello Santini $^{6}$ (D)
}

Received: 19 January 2021 / Accepted: 13 May 2021 / Published online: 18 June 2021

(c) The Author(s) 2021

\section{Abstract}

Medicinal plants always are part of folk medicine and are nowadays receiving worldwide attention for prophylaxis, management, and treatment of several diseases, as an alternative to chemical drugs. The current work provided a comprehensive overview and analysis of the Astragalus and health relationship in literature. The analysis of their therapeutic potential is thus instrumental to understand their bioactivity. Among these, the flowering medicinal plant Astragalus membranaceus has raised interest due to several beneficial health effects. This perspective review discussed the botanical, geographical, historical, and the therapeutic properties of A. membranaceus, with a special focus on its health improving effects and medicinal applications both in vitro and in vivo.

\section{Graphic abstract}

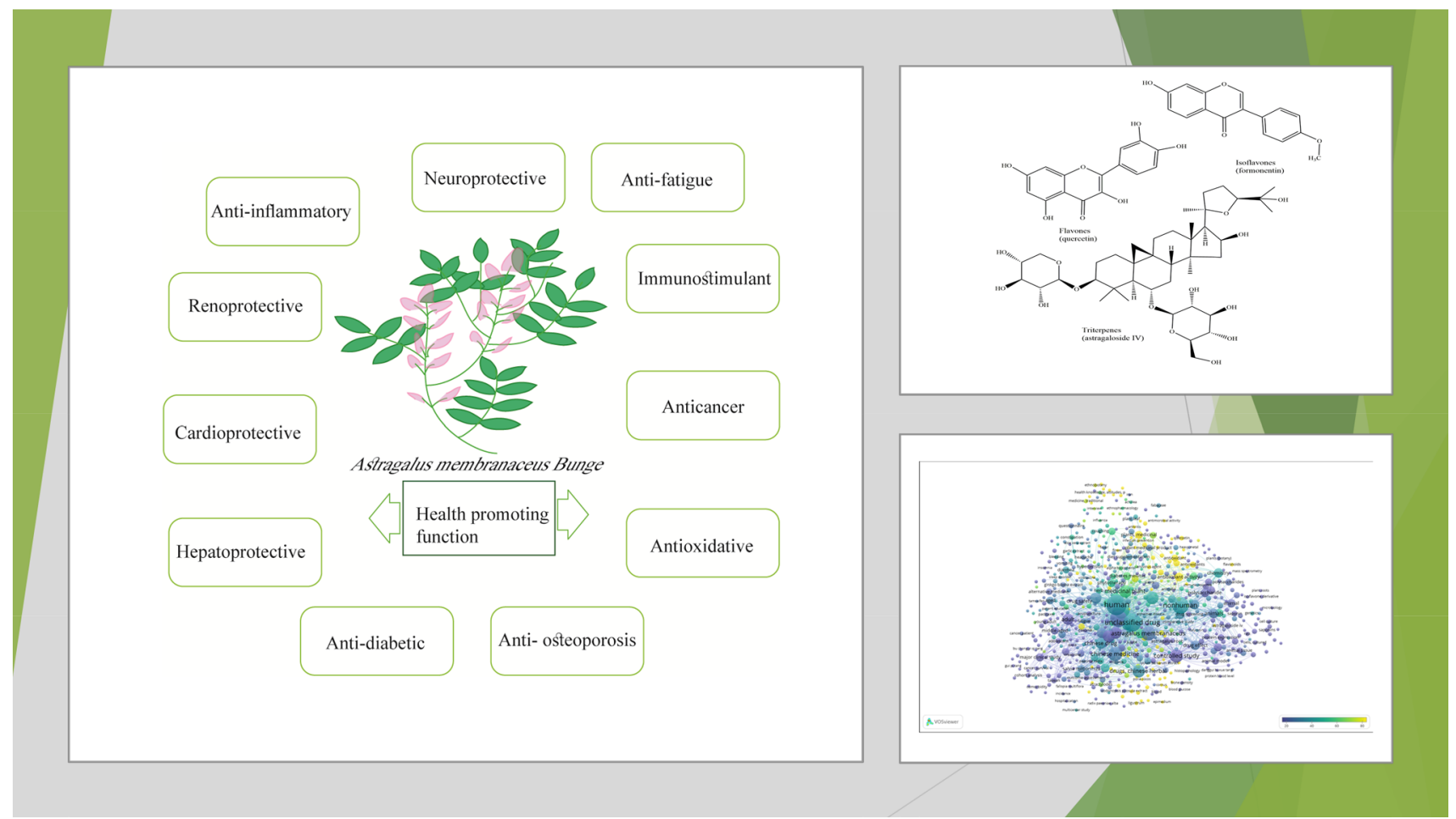

Extended author information available on the last page of the article 
Keywords Astragalus membranaceus bunge $\cdot$ Botany $\cdot$ Biodiversity $\cdot$ Territory $\cdot$ Herbal medicine $\cdot$ Bioactive compounds · Biological properties $\cdot$ Medicinal applications $\cdot$ In vitro studies $\cdot$ In vivo studies

\section{Introduction}

Medicinal plants have long been used as a global strategy for the treatment of various diseases (Izzo et al. 2016). The International Union for the Conservation of Nature (IUCN) declared the use of 50,000-80,000 medicinal plants for medicinal purposes (Chen et al. 2016) in line with biodiversity and sustainability concept (Guarino and Pignatti 2010; Pignatti and Cipriani 2010; Pignatti 2013; Attore et al. 2018). Astragalus membranaceus (Fisch.) Bunge (syn. Astragalus propinquus Schischkin) is a plant from the Fabaceae (or Leguminosae) family, and a flowering medicinal plant for which several beneficial effects have been identified, e.g., cardio; neuro; reno; and hepatoprotection, hypoglycemic, anti-osteoporosis, anti-fatigue, anti-inflammatory, anti-cancer, antioxidant, and immune system boosting. The geographical distribution of this plant has been reported at the edge of mountains and scattered forests and grasslands, which grow predominantly in the inner Mongolia autonomous region and the northeastern regions of Heilongjiang Province, China, as well as traditional medicine widely used the Radix Astragali, the dried root of A. membranaceus var. Commercial sales volume of Astragalus mongolicus is estimated at more than 10 million tons per year (Zhang et al. 2019). The purpose of this review article is to investigate the botanical, geographical and historical characteristics of A. membranaceus, in addition to gathering information about the main components and therapeutic purposes of the plant.

\section{Astragalus and health: quantitative literature analysis}

The current work provides a comprehensive overview and analysis of the Astragalus and health relationship in the literature. In January 2021, this search was conducted through the Scopus database to Astragalus and health publications. Bibliometric data were extracted from the Scopus online database using the search string: "Astragalus" and "Health". Bibliographic data were recorded, such as the publication year, publication count, citation count, subject area, countries/territories, institutions, document type the "Analyze" and "Create Citation Report" functions of the Scopus web online platform have been used for the basic analyses. The "full records and cited references" were exported to VOSviewer software (version 1.6.16, VOSviewer software website) for further bibliometric analyses and additional processing.
The VOSviewer software (v.1.6.16, 2020) analyzes the terms/words used in the titles and abstracts of publications, by breaking down the paragraphs into words and phrases, linking them with the citation data of the publications, and visualizes the results in the form of a bubble map using a term map with default settings (Van Eck and Waltman 2009, 2010, 2011; van Eck 2011; Waltman et al. 2010), Default parameters were used for the analyses and visualizations; particularly, the type of analysis was based on co-occurrence; as unit of analysis, all keywords were considered (author and index keywords), and the counting method was full counting. Create a map based on bibliographic data to create a co-authorship, keyword co-occurrence, citation, bibliographic coupling was selected. In a term map, the size of a bubble represents how frequently a term is mentioned in the articles-the frequency of appearance of a term (multiple mentions in one article were counted once). Two bubbles are positioned more closely to each other if the terms co-appeared more often in the analyzed publications. The color of a bubble reflects the average citations per publication (citations per publication, CPP).

To simplify the bubble map, words/terms that appeared in at least five publications have been analyzed and visualized. As per the threshold chosen, the minimum number of occurrences of keyword was set up to 5 . Of the 8502 keywords, 678 meet the selected threshold and three of them were manually excluded. This search strategy identified publications that mentioned the relevant words or their derivatives in the title, abstract, or keywords. As a result, the following parameters were assessed: publication year, publication count, citation count, institution, country/territories, and document type.

The search returned 392 publications covering the time period from 1973 to 2021 that were collectively cited 10,270 times, with an H-index of 55 and $26.19 \mathrm{CPP}$ as an average.

A total of 675 terms have been derived from the quantitative literature research on 392 publications and they are visualized as a term map (Fig. 1). The top 10 recurring keywords are listed in Table 1. It is interesting to notice that among the top 10 recurring keywords appears as Astragalus membranaceus, which shows as the research is mainly focused on the biological activities of this species.

Publications and citation trends of relationship between Astragalus and health research are reported in Fig. 2.

The type of documents related to the 392 publications with regard to Astragalus membranaceus retrieved was distributed as reported in Fig. 3. "Article" and "Review" account for the $65.8 \%$ and $25.8 \%$, respectively, followed by "Conference paper" (3.6\%) and "Book chapter" (2.3\%). 
Figures 4 and 5 show, respectively, the most productive countries/territories and institutions with regard to Astragalus membranaceus. Regarding countries/territories, the most productive was China $(n=175, \mathrm{CPP}=20.41)$, followed by United States $(n=52, \mathrm{CPP}=27.23)$ and Taiwan $(n=30$, $\mathrm{CPP}=14.87$ ).

The most productive institution with regard to Astragalus membranaceus was China Medical University Taichung $(n=17, \mathrm{CPP}=9.18)$. All Top 10 Institutions are in China and have at least or more 6 publications.

\section{The botanical, geographical, and historical aspects of Astragalus (Astragalus membranaceus Bunge)}

Astragalus membranaceus has been used as a valuable medicinal plant, especially in traditional Chinese medicine (TCM), also known as Huang Qi, in Chinese, Ogi, in Japanese, Milk-Vetch, in English, and Gavan, in Persian (Shahrajabian et al. 2019). The geographical distribution of this genus, which is estimated to have 2000-000 different species, has been reported throughout the arid and temperate regions of the world ( $\mathrm{Li}$ et al. 2014a), including about 120 species in Europe, 150 species in South American, 500 species in North American, and 1500 species in Asia. The main habitats of A. membranaceus are along sandy rivers, shrub edges, and sunny slopes. The main botanical characteristics defined for this perennial plant with $50-150 \mathrm{~cm}$ high, include a straight and long (up to $50 \mathrm{~cm}$ ) cylindrical root, erect stems branched in the upper parts with small ovate-lanceolate or elliptical leaves with 7-30 mm long and 4-10 mm wide (13-31 lobular pieces), light yellow corolla, puberulous ovary, and black undercoated apex beaked and $2-2.5 \mathrm{~cm}$ ovate-oblong pods ( $\mathrm{Fu}$ et al. 2014). This plant blooms from June to July and fruiting occurs from August to September. A. membranaceus dried root (Astragali Radix) has been consumed over 2000 years due to health-promoting effects. Traditional Chinese medicine recommended A. membranaceus to treat various gastrointestinal disorders, including intestinal inflammation, chronic phlegmatic disorders, chronic diarrhea, and stomach ulcer (Bratkov et al. 2016).

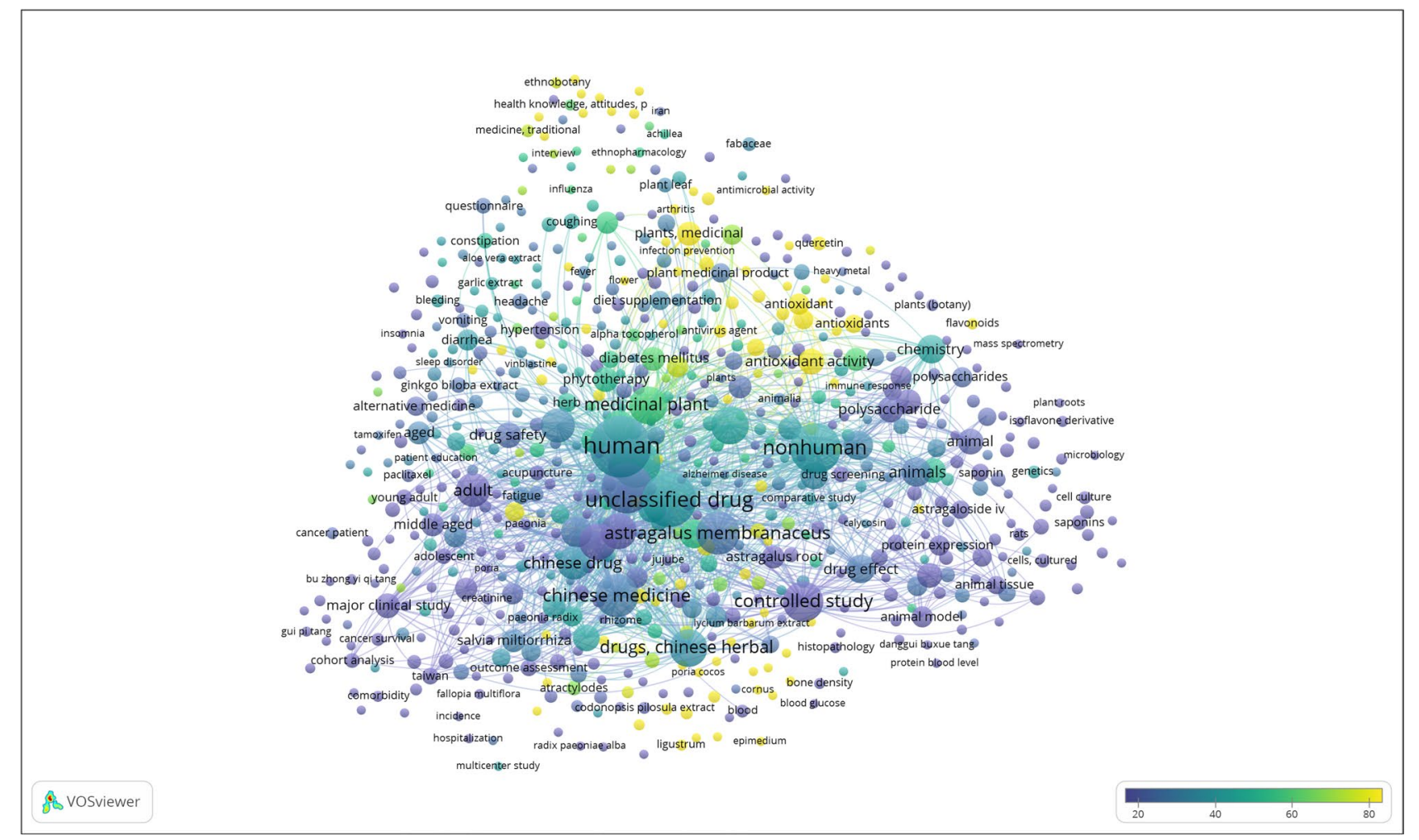

Fig. 1 Term map for relationship of Astragalus and health research. Bubble size represents the number of publications. Bubble color represents the citations per publication (CPP). Two bubbles are closer to each other if the terms co-appeared more frequently. (Bibliometric data were extracted from the Scopus online database and elaborated by VOSviewer software) 
Table 1 The top 10 recurring terms on the relationship Astragalus and health research. (Bibliometric data were extracted from the Scopus online database and elaborated by VOSviewer software)

\begin{tabular}{lll}
\hline Term & Occurrence & $\begin{array}{l}\text { Total link } \\
\text { strength }\end{array}$ \\
\hline Human & 229 & 6699 \\
Unclassified drug & 174 & 5255 \\
Non-human & 154 & 4329 \\
Herbaceous agent & 152 & 4661 \\
humans & 140 & 4384 \\
Chinese medicine & 112 & 3355 \\
Astragalus membranaceus & 112 & 3001 \\
Controlled study & 97 & 2883 \\
Medicinal plant & 87 & 2642 \\
Drugs, Chinese herbal & 87 & 2783 \\
\hline
\end{tabular}

\section{Main components of pharmaceutical character of Astragalus membranaceus}

The main reported chemical constituents of A. membranaceus (Fig. 6) were triterpenes, polysaccharides, flavonoids, and saponins ( $\mathrm{Li}$ et al. 2014a, b). The presence of compounds such as terpenoids and flavonoids that usually occur in free or glycosidic form is of relevant pharmacological interest due to the bioactivities attributed to these classes of compounds. The flavonoids include flavonols, flavones, flavanones, and isoflavonoids which have been described as having many types of bioactivities. Compounds extracted with $75 \%$ methanol from different parts of Astragalus (roots, stems, leaves, petioles, and flowers) were analyzed by UPLC-MS/MS technique, to evaluate flavonoids and triterpenoids distribution, together with 13 of their metabolites, showing that isoliquiritigenin, liquiritigenin, daidzein, and bioactive isoflavones accumulate in both roots and flowers (Liu et al. 2018). The content in the isoflavones, calycosin, and calycosin$7-O-\beta$-D-glucoside, was found to be the highest in the leaves and roots of $A$. membranaceus, as revealed by HPLC analysis (Kim et al. 2014). With calycosin content in leaf $(145.56 \mu \mathrm{g} / \mathrm{g} \mathrm{DW})$ higher than in root $(1.64 \mu \mathrm{g} / \mathrm{g}$ $\mathrm{DW})$, while calycosin-7- $O-\beta$-D-glucoside content in root $(4.88 \mu \mathrm{g} / \mathrm{g}$ DW) higher than leaf in $(2.0 \mu \mathrm{g} / \mathrm{g} \mathrm{DW})(\mathrm{Kim}$ et al. 2014). Kwon et al. (2013) analyzed the content in Astragalosides, known as the highly bioactive compound in A. membranaceus root, and reported that Astragalosides are more concentrated in periderm and cortex than in xylem; and that unpeeled roots were richer in these compounds. Zhang et al. (2011) isolated 24 secondary metabolites (isoflavonoids, astragalasides, and benzoquinone) from A. membranaceus roots, and the (-)-methylinissolin 3-O- $\beta$-D-glucosidewas detected for the first time in this study, and shown to possess potent anti-inflammatory activity, evaluated by the inhibition of nitric oxide

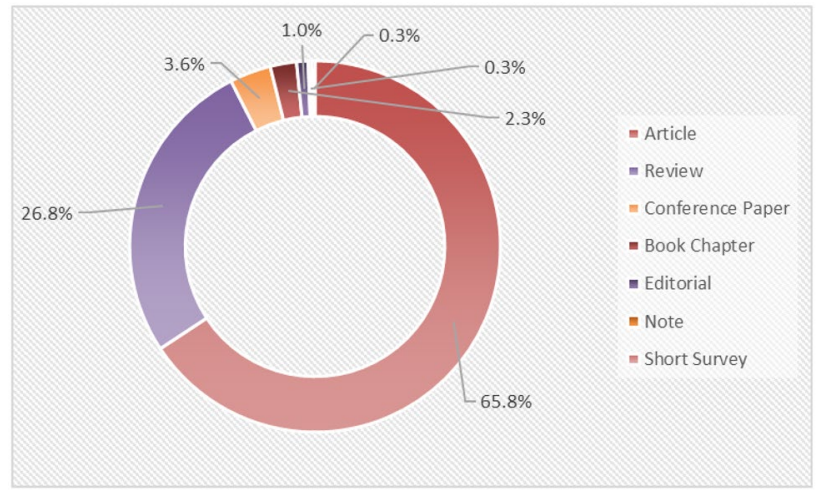

Fig. 3 Distribution of documents with regard to Astragalus membranaceus by type. (Bibliometric data were extracted from the Scopus online database)
Fig. 2 Publication and citation trends of relationship between Astragalus and health research. (Bibliometric data were extracted from the Scopus online database)

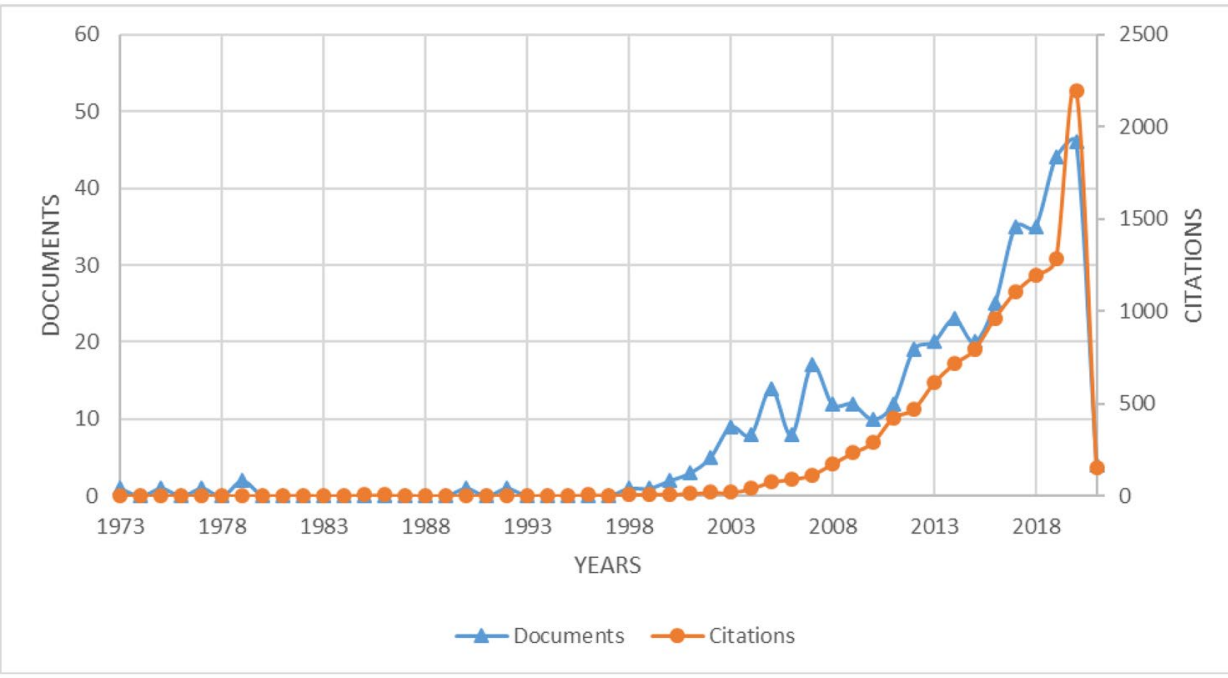


Fig. 4 Most productive countries/territories with regard to Astragalus membranaceus. (Bibliometric data were extracted from the Scopus online database)
Fig. 5 Most productive institutions with regard to Astragalus membranaceus. (Bibliometric data were extracted from the Scopus online database)
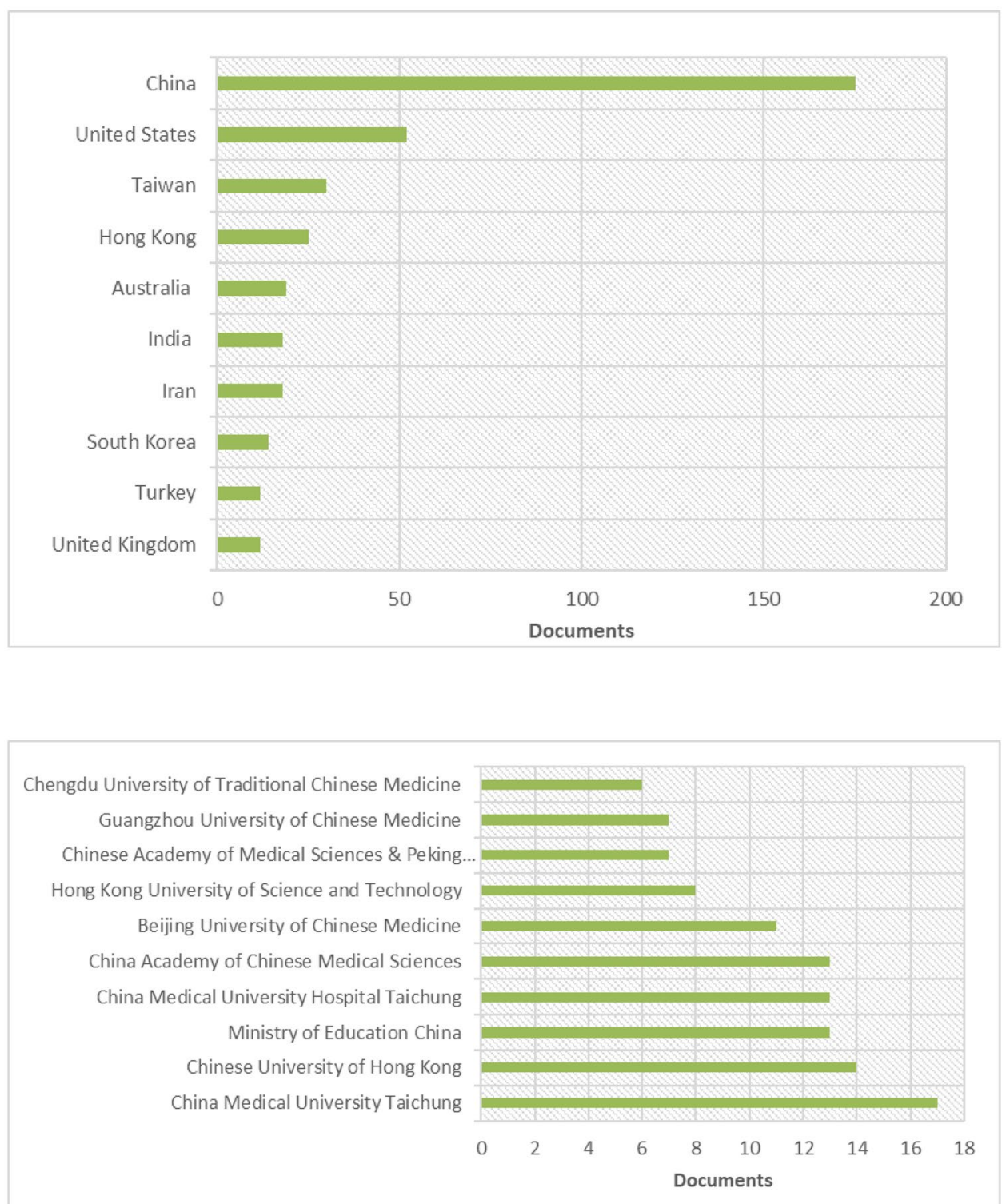

(NO) released by lipopolysaccharide (LPS)-stimulated macrophages (RAW 264.7 cells). Ethanolic extract of Astragali Radix, analyzed by RP-HPLC, main content included triterpene saponins, namely astragaloside I-IV, isoflavonoids (formononetin and calycosin) which are the main bioactive compounds (Lee et al. 2017).

\section{In vitro and in vivo therapeutic potentials of Astragalus (Astragalus membranaceus): an update shot}

The evaluation of phytochemical composition can be considered as the first step for the determination of the beneficial health properties of a plant, as it permits a preliminary approach on the assessment of chemical compound structure-related activities (Souto et al. 2019). Figure 7 shows the potential beneficial effects of this plant, e.g., neuroprotection (Chan et al. 2009), renoprotection (Yin et al. 2004; Wen et al. 2020), hepatoprotection (Ali et al. 2018), hypoglycemic (Kai et al. 2015), anti-osteoporosis (Koo et al. 2013), anti-fatigue (Berezutsky et al. 2019), antiinflammatory (He et al. 2012), immune system boosting (Lee et al. 2003), anti-cancer (Chen et al. 2019), antioxidant (Lee et al. 2011), and cardioprotection (Zhang et al. 2006). 
Fig. 6 Some main compounds present in A. membranaceus<smiles>COc1ccc(-c2coc3cc(O)ccc3c2=O)cc1</smiles>

\subsection{Health-promoting activities of Astragalus (Astragalus membranaceus) based on in vitro studies}

Many health-promoting effects have been reported for $A$. membranaceus extracts. Table 2 shows the results of the main in vitro studies found in the literature. Zhang et al. (2020a, b) reported the main pharmacological effects of Astragaloside-IV, a major compound obtained with aqueous extraction, including neuroprotection, hepatoprotection, anti-diabetic anti-cancer activity, which were correlated with the antioxidant and anti-inflammatory activities exhibited by the modulation of various signaling pathways. These authors suggested the need for bioinformatics analysis to determine the effective Astragaloside-IV targets, for prediction of drug-target interaction (Zhang et al. 2020a). The
A. membranaceus dried root extract ( $70 \%$ ethanol extract) showed anti-diabetic effect by increasing glucose-stimulated insulin production and secretion from INS-1 cells, action attributed to the extract compounds nucleoside adenosine, formononetin, and calycosin-7-O- $\beta$-D-glucoside by pathways that result in the activation of peroxisome proliferatoractivated receptor- $\gamma$ (PPAR- $\gamma$ ) and pancreatic and duodenal homeobox-1 (PDX-1) transcription factors, activation of phosphorylation of Akt, phosphatidylinositol 3-kinase (PI3K) pathway, through insulin receptor substrate-2 (IRS-2) (Lee et al. 2019). Formononetin (7-hydroxy-4'methoxyisoflavone) was shown potential to treat diabetic retinopathy as it inhibited the vascular endothelial growth factor (VEGF) secretion, from a retinal cell model, through the HIF-1 $\alpha$ /VEGF signaling pathway, compromising retinal neovascularization and reducing the expressions of PHD-2 
Fig. 7 Scheme of the Astragalus membranaceus Bunge therapeutic properties

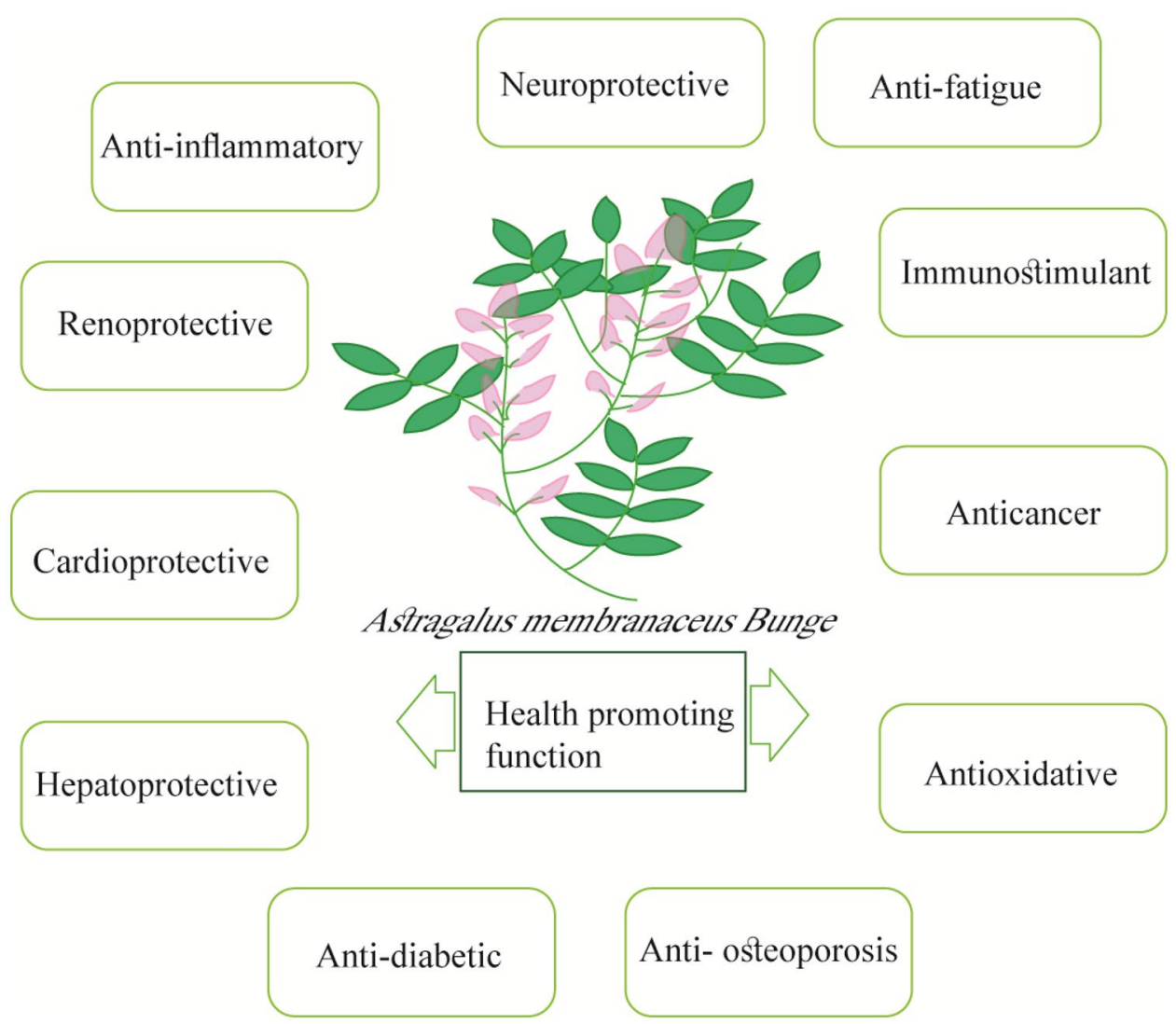

(prolyl hydroxylase-2), HIF-1 $\alpha$ (hypoxia-inducible factor 1-alpha), and VEGF proteins (Wu et al. 2016). Anti-diabetic effect of Astragalus polysaccharide and Berberine, through improvement of insulin resistance by activation of several genes and signaling pathways in HepG2 cells that decrease reactive oxygen species (ROS) concentration and increasing the cell survival rate was also reported (Lin and Mao 2020). Astragalus polysaccharides resulted in a reduction in cellular apoptosis through the modulation of $\mathrm{Bcl}-2 / \mathrm{Bax}$ ratio and the prevention of pro-apoptotic protein expression in both intrinsic and extrinsic pathways (Sun et al. 2017).

In a study, the administration of Astragalus extract decreased the viability and induced the apoptosis of gastric cancer cell line via the AMPK pathway (Song et al. 2020). Zhang et al. (2018a) investigated that the ovarian cancer cell invasion and migration were inhibited through a decrease in the phosphorylation of ERK and the expression of MMP2/9 (Zhang et al. 2018a). Astragalus extracts induced apoptosis in non-small cell lung cancer cell line, by increasing cleaved caspase-8, -9 expression (Zhou et al. 2018). Others show that Astragalus polysaccharides induced cell-cycle arrest in 4T1 cells (Park and Park 2018). Jiang et al. (2019) reported the anti-cancer activity of formononetin as resulting from mechanisms involving halting metastasis, arresting cell cycle and inducing apoptosis, the $\mathrm{IC}_{50}$ value of $1 \mu \mathrm{M}$ for Formononetin against CNE2 (nasopharyngeal cell line) was reported. Wang and $\mathrm{Ba}$ (2015), analyzed the chemical composition of Astragali Radix ethanol extract using HPLC and NMR spectroscopy, and identified several compounds including (3R)-8,2' -dihydroxy-7,4'-dimethoxyisoflavan, 7,2'-dihydroxy-3',4'-dimethoxy-isoflavan-7,2' -dioxo- $\beta$ D-glucoside, uridine, and astragaloside, which induced increase in the apoptosis rate of HepG2 cells, as evaluated by flow cytometry and MTT assay. Anticancer properties were also reported for the combination of apatinib [selective tyrosine kinase inhibitor of endothelial growth factor receptor-2 (VEGFR-2)] and Astragalus polysaccharide by enhancing cellular autophagy and blocking AKT pathway (Wu et al. 2018). The aerobic glycolysis metabolism of colorectal cancer cells (SW620 and HT-29 cell lines) was prevented by the administration of Astragalus saponins at the doses $50 \mu \mathrm{g} / \mathrm{ml}$; the IC50 values of 35 and $46 \mu \mathrm{g} / \mathrm{ml}$, at $24 \mathrm{~h}$, for HT-29 and SW620 cells, respectively, revealed anticancer activity, confirmed by a significant reduction in the number of colony formation, after a treatment with $25 \mu \mathrm{g}$ / $\mathrm{ml}$ for 2 weeks (Guo et al. 2019). In an in vitro study, the pancreatic cancer cell growth was inhibited by the calycosin, extracted from A. membranaceus, via the induction of apoptosis and arrest of cell cycle (Zhang et al. 2020b). Calycosin exhibited anti-proliferative activity and inhibit cell migration in a human colorectal cancer cell model (HCT-116 cells), by mechanisms that involve up-regulation of ER $\beta$ and PTEN 


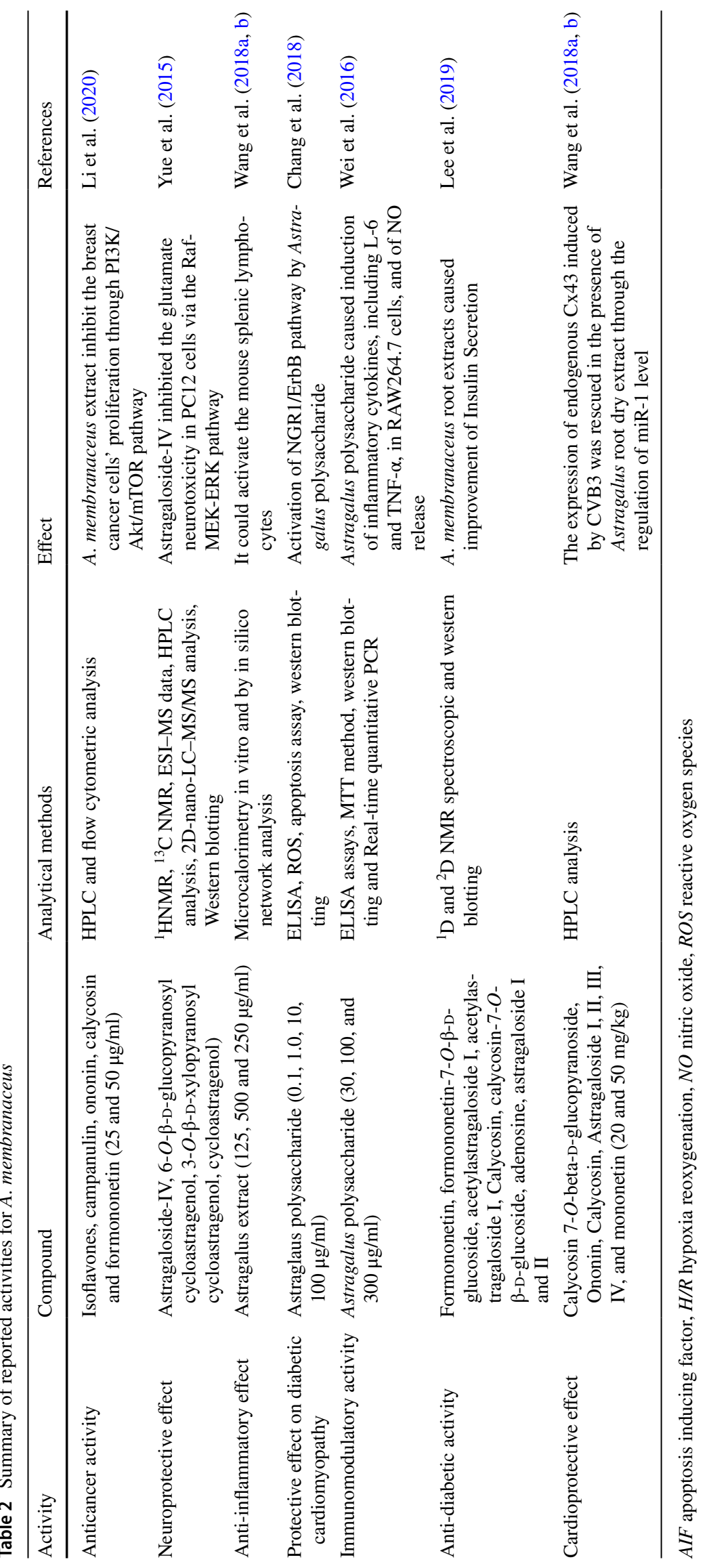


(phosphatase and tensin homolog deleted on chromosome ten) and downregulation of the micro-RNA miR-17, probably through regulation of miR-17/PTEN/Akt pathway (Chen et al. 2015).

Anti-myocardial H/R damage effect and regulation of the PI3K/Akt/HO-1 signaling pathway reported in a study by Yang et al. (2019).

In a study by Adesso et al. (2018), performed with rat intestinal crypt cell line (IEC-6 cells) co-exposed to the interferon- $\gamma$, lipopolysaccharide derived from $E$. coli (LPS) and A. membranaceus extract $(5-100 \mu \mathrm{g} / \mathrm{ml})$ showed that the extract of A. membranaceus root produced anti-inflammatory effect that was reported by reducing the activation of nuclear factor- $\mathrm{kB}(\mathrm{NF}-\mathrm{\kappa B})$, the formation of nitrotyrosine, the expression of inducible nitric oxide synthase (iNOS) and of cycloxygenase-2 (COX-2), as well as the release of tumor necrosis factor- $\alpha$ (TNF- $\alpha$ ). Adesso et al. (2018) also showed the antioxidant properties of A. membranaceus extract against hydrogen peroxide-induced oxidative stress by reducing ROS levels and by increasing expression of antioxidant cytoprotective factors, the activation of nuclear factor (erythroid-derived 2)-like 2 (Nrf2). Flavonoids of Astragalus extract exhibited anti-inflammatory and immunomodulatory properties in LPS-induced RAW 264.7 cells by blocking the expression of nuclear NF- $\mathrm{kBp} 65$ and the phosphorylation of JNK and p38 in the NF- $\mathrm{KB}$ and MAPKs pathway, respectively, and by reducing the levels of COX-2 and iNOS (Li et al. 2018). Total flavonoids extracted from Astragalus regulated the formation of NO, IFN- $\gamma$, IL-6, IL-1 $\beta$, and TNF- $\alpha$ in RAW 264.7 macrophages, resulting in in vitro anti-inflammatory and immunomodulatory properties (Guo et al. 2016). The Astragalus saponins induced an anti-inflammatory effect by inhibiting LPS-induced NF- $\kappa B$ pathway resulting in decreased expression of iNOS (Wang et al., 2016). In a study using a standardized extract containing A. membranaceus and two other Korean herbs, KBH-JP-040 extract, caused anti-osteoarthritis potential by inhibiting JNK/p38 MAP-kinase pathway and preventing the production of NF- $\kappa \mathrm{B}, \mathrm{I} \kappa \mathrm{B} \alpha$, matrix metalloproteinase, and inflammatory cytokines (Rahman et al. 2018). Astragaloside-IV $(100 \mu \mathrm{M})$ prevented myocardial remodeling and fibrosis in rat cardiomyocytes [H9C2(2-1)]] cell line through reduction in the activity levels of Sirt1, Bcl-2, miR-34a, as well as increasing superoxide dismutase activity and reduction of lipid peroxidation (Zhu et al. 2019). Astragalus polysaccharide could protect the cardiomyocyte cell line (H9c2) by reducing apoptosis induction that elevated cell viability, and by inhibiting the NF- $\mathrm{KB}$ and JNK pathways that suppressed the production of the inflammatory cytokines, possible as a result of down-regulation of miR-127 expression (Ren et al. 2018).

Elevation in the immunosuppressive and the proliferative activities of umbilical cord-derived mesenchymal stem cells has been attributed to the reduction in the serum levels of IL-1 $\beta$, IFN- $\gamma$, MCP-1, IL-6, and TNF- $\alpha$ (Chao et al. 2017).

The Bcl-2/Bax mRNA ratio, and GPx and SOD activities were increased, and the expression level of Bax mRNA was reduced in the interstitial cells of Leydig in rats (Jiang et al. 2015).

However, Kumar et al. (2018) reported that A. membranaceus root extract altered the cytochrome P450 2B6 (CYP) activity, a reduction in CYP2B6 activity caused by ethyl acetate and ethanol extract was observed, $\mathrm{IC}_{50}$ values of 29.7 and $53.37 \mu \mathrm{g} / \mathrm{ml}$, respectively. These results may indicate potential adverse drug interactions with CYPs, when $A$. membranaceus is co-administered with drugs metabolized by CYP2B6.

The antiviral activity of A. membranaceus against influenza virus was shown in infected mouse Raw 264.7 cells by influencing the cell proliferating cycle, and by affecting the TLR3 signaling pathway, by reducing the malondialdehyde level, and increasing the superoxide dismutase level (Liang et al. 2019). Antibacterial activity of the aqueous Astragalus extract was demonstrated, as this could mildly inhibit bacterial responsible by dysentery and diarrhea while not affecting normal gut bacteria (Lai et al. 2018).

\subsection{Health-promoting activities of Astragalus (Astragalus membranaceus) in animal models}

Several health-promoting effects have been documented for A. membranaceus extracts in animal models. Table 3 shows the results of the main studies in animal models using $A$. membranaceus extracts. Wei et al. (2020) reported that the administration of $5 \mathrm{mg} / \mathrm{kg} /$ day of Astragaloside-IV in male Sprague-Dawley rats for 2 weeks treated cardiac fibrosis by declining the expression of collagen I, alpha-smooth muscle actin ( $\alpha$-SMA), and transient receptor potential melastatin-7 (TRPM7) as well as by inhibiting the activity of TGF- $\beta$ / Smads pathway. Administration of Astragalus polysaccharides in diabetic cardiomyopathy rat model (induced with streptozotocin, STZ) prevented the cardiomyocyte apoptosis due to down-regulation of PERK-ATF6-CHOP pathways of endoplasmic reticulum stress, which was also observed in vitro in high glucose-induced H9C2 cells (Sun et al. 2019). In a study by Cao et al. (2017), administration of $1.5 \mathrm{~g} / \mathrm{kg} /$ day of Astragalus polysaccharide for 3 days improved the cardiomyocyte function in mice with doxorubicin-induced heart failure, so that the induced heart failure by disturbing cardiomyocyte autophagic flux resulted in cell apoptosis that was reduced after Astragalus polysaccharide treatment through regulation of AMPK/mTOR pathway, decreasing doxorubicin-induced cardiotoxicity and restoring normal autophagic flux. In another study, administration of astragaloside IV shows protective effect through elevation in the level of oxygen consumption ratio and reduction in the 
anaerobic glycolysis in mice with heart failure (Dong et al. 2017). Improvement of endothelial dysfunction, oxidation, matrix metalloproteinase (MMP)-2/9 function because of daily administration of Astragalus polysaccharides (128 mg/ $\mathrm{kg})$, Astragalus total flavonoids $(72 \mathrm{mg} / \mathrm{kg})$, and Astragalus saponins $(22 \mathrm{mg} / \mathrm{kg})$, total extract of A. membranaceus $(196 \mathrm{mg} / \mathrm{kg})$ for 6 weeks in rats with hyperhomocysteinemia (HHcy) (Qiu et al. 2017). The cardioprotective activity of Astragaloside-IV was found following the down-regulation of miR-92a/-23a through the MAPK/ERK and PI3K/AKT signaling pathways (Gong et al. 2018). The administration of Astragalus polysaccharides ( $200 \mathrm{mg} / \mathrm{kg} \mathrm{b.w}$ ) elevated the antioxidant activity by declining apoptosis and preventing ROS-elicited oxidative damage (Awad et al. 2020). Chen et al. (2018) show that Astragalus extract inhibited oxidative damage and ROS production, dropped progenitor cell apoptosis, and enhanced enzyme activities, SOD2 protein levels, the CSPCs' cell proliferation, and CSPC abundance. Treatment with astragaloside IV inhibited type I collagen synthesis and isoprenaline-induced cardiac fibrosis proliferation through dropping the activation of ROS-mediated MAPK signaling pathway (Dai et al. 2017). Yu et al. (2017) reported taking $2.5 \mathrm{mg} / \mathrm{kg}$ of astragaloside in rats for 4 weeks prevented myocardial infarction-induced damage by upregulating Jagged1, Notch1, and HIF-1 $\alpha$ expression. Others show that taking $80 \mathrm{mg} / \mathrm{kg} /$ day of Astragaloside-IV in rats reduced energy metabolic disturbance and pressure overload-induced hypertrophy via PGC- $1 \alpha / \mathrm{PDK} 4 / \mathrm{CPT}-1$ pathway (Lu et al. 2016).

Administration of Astragalus in arthritis-induced rats for 4 weeks showed anti-arthritic properties attributed to the prevention of inflammatory mediators (Liu et al. 2017). The reduction in immune organ index, inflammatory cell infiltration, synovial hyperplasia and paw swelling, and the elevation of body weight have also been described (Maresca et al. 2017). The administration of $300 \mathrm{mg} / \mathrm{kg}$ per os of the hydroalcoholic extract of Astragali radix in a rat model showed anti-arthritic activity and relieved the pain by 96\% and 78\% of complete Freund's adjuvant and monoiodoacetate injection, respectively (Maresca et al. 2017). The daily co-administration of Salvia miltiorrhiza with A. membranaceus $(10 \mathrm{ml} / \mathrm{kg} \mathrm{SM}$ and $0.59 \mathrm{~g} / \mathrm{ml} \mathrm{AM})$ in rats with LPS-induced acute lung injury for 3 consecutive days down-regulated the TLR4/IRAK/NF- $\mathrm{BB}$ signaling pathway and thus declined inflammatory cytokine release, vascular leakage and lung wet/dry weight ratio, and improved lung histopathological changes (Qin et al. 2018). In a study by Wang et al. (2019), treatment of mice with astragaloside IV $(0.01 \mathrm{mg} / \mathrm{g})$ by gavage for 6 days showed anti-inflammatory activity by inhibiting JNK, p38, and NF- $\mathrm{KB}$ signaling pathways, resulting in reduced the consequences of LPS-induced endometritis like the levels of myeloperoxidase (MPO), NO, TNF- $\alpha$, and IL- $1 \beta$. The administration of astragaloside at $40-80 \mathrm{mg} / \mathrm{kg}$ in rats for 10 weeks could significantly manage diabetic nephropathy by blocking the $\mathrm{Wnt} / \beta$ catenin signaling pathway, anti-epithelial-mesenchymal transition, anti-inflammatory, and anti-oxidative stress activities (Wang et al. 2020). The administration of Astragalus polysaccharide in male Sprague-Dawley rats enhanced bone marrow mesenchymal stem cell (BMSC) differentiation and proliferation by triggering $\mathrm{Wnt} / \beta$-catenin and PI3K/AKT pathways through bone morphogenetic protein type 9 (BMP9) overexpression and miR-152 down-regulation ( $\mathrm{Li}$ et al. 2019a, b). Daily administration of Astragalus polysaccharide, in ovariectomized rats, for 3 months, alleviated the osteoporosis caused by oxidative stress via the regulation of FoxO3a/Wnt $2 / \beta$-catenin pathway $(\mathrm{Ou}$ et al. 2019). Astragaloside-IV extract administration to rats with ischemia-reperfusion injury showed neuroprotective activity, regulated the expression of apoptosis-related genes, improved the pathological brain damage and declined the cerebral infarction volume (Yin et al. 2020). Administration of Astragali Radix in mouse model of ischemia-induced brain damage for 3 days suppressed the expression levels of Aquaporin-4 (AQP-4) mRNA and protein, and that caused a reduction in water content, edema, and brain infarct size (Lim et al. 2019). Taking $10 \mathrm{~g} /$ day of Astragalus in mice inhibited the progression of renal fibrosis through the down-regulation of E-cadherin expression, the inhibition of TGF $\beta$-R1, TGF- $\beta 1$ and $\alpha$-SMA expression, and the reduction in blood glucose levels (Yi et al. 2016). In a study by $\mathrm{Li}$ et al., anti-edema activity of Astragaloside-IV reported through the regulation of Matrix metalloproteinase-9 and aquaporin 4 ( $\mathrm{Li}$ et al. 2013).

Rats treated with Astragalus polysaccharides exhibited an increase in the immunity function and a prevention of spleen deficiency by interfering with Toll-like receptor 4 (TLR4) and regulating inflammatory cytokines, respectively (Zhao et al. 2019). The Sheng-Nao-Kang decoction containing $A$. membranaceus extract exerted antithrombotic effect in rats by balancing the prostacyclin (PGI2) and thromboxane A2 (TXA2) ratio (PGI2/TXA2), the anticoagulation activity and regulating the active substances produced by vascular endothelium (Dang et al. 2015). Li et al. (2019a, b) used an aqueous Astragalus extract, mainly composed of flavonoids, saponins, and polysaccharides, and then evaluated its immunomodulatory potential in mice at a dose of $1 \mathrm{~g} / \mathrm{kg}$ twice a day for 18 days, and showed an improvement in the immune responses such as serum IgG and IgM levels, spleen lymphocyte subset, NK-cell activity, splenocyte proliferation, thymus and spleen parameters, peripheral white blood cell count, and body weight gain. Yu et al (2018) reported antitumor activity, following the administration of alcoholsoluble A. membranaceus polysaccharide extract $(100,200$, and $300 \mathrm{mg} / \mathrm{kg}$ ), for 15 days in murine $\mathrm{H} 22$ heptoma cells, tumor cell apoptosis was induced due to an enhancement 


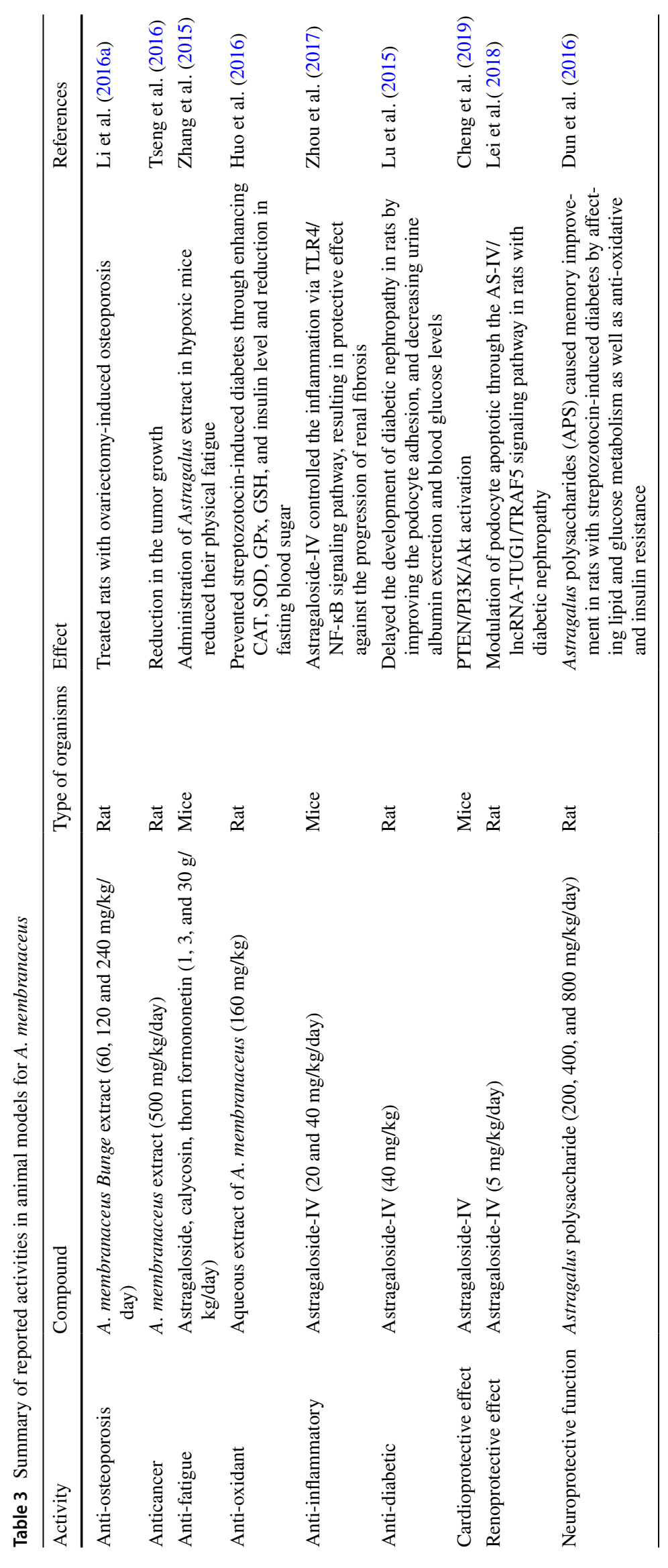


of immune cell (NK cells, lymphocytes and macrophages) activities and serum levels of cytokines (IFN- $\gamma$, IL-2, and TNF- $\alpha$ ). The administration of A. membranaceus decoction for a week prevented the intestinal mucosal damage due to the inhibition of inflammatory cytokine activity (Cui et al. 2018). Astragaloside-IV modulated the host immune system through the excessive production of inflammatory mediators and the suppression of inflammation (Li et al. 2016b). Diabetic podocyte damage was decreased due to Panax notoginseng co-administrated with A. membranaceus via Nox4 and Bax down-regulation as well as Bcl-xl, $\alpha$-dystroglycan, and nephrin up-regulation (Zhai et al. 2019).

In a mice model of infertility, treated with Astragalus root extract showed improvement within 56 days due to PPAR $\alpha$ agonistic activity, so that the expression of ovarian PPAR $\alpha$ mRNA and uterine was up-regulated for 1.5- and 2.5-fold, respectively (Orkhon et al. 2018). Co-administration of Laminaria japonica extract with A. membranaceus extract $(200-400 \mathrm{mg} / \mathrm{kg}$ ) in rats, for 6 weeks, attenuated the dyslipidemia and hypothyroidism caused by propylthiouracil (Mohibbullah et al. 2019). Kim et al. (2016) evaluated the effects of A. membranaceus $(100,500,1000 \mathrm{mg} / \mathrm{kg}$ ) for 5 days a week for 5 weeks in mice, and reported an increase in the expression of cAMP response element modulator and activator of CREM in testis, as well as increased sperm value, motility, and count.

\subsection{Health-promoting activities of Astragalus (Astragalus membranaceus) in humans, with particular regards to clinical trials}

There are several clinical trials evaluating the therapeutic effects of A. membranaceus extract. Table 4 summarizes the results of the main clinical trial studies. In the literature, there are some reports of anti-cancer activity attributed to the main compounds extracted from A. membranaceus, tested under clinical conditions, although only few studies report the improvement of the bioavailability of these compounds. Mao et al. (2020) reported a study in patients with myocardial infarction who received Tongguan Capsules (TGC), containing a mixture of various herbs (A. membranaceus, Borneolum syntheticum, Salvia miltiorrhiza, and Grasshopper), at a dose of $4.5 \mathrm{~g} /$ day, for 6 months, in addition to the standard medication; in comparison to control group (only standard medication), the TGC-receiving patients shown significant reduction of left ventricular end-systolic volume index as well as lower incidence of the major adverse cardiovascular events, a decrease in myocardial markers of fibrosis and apoptosis, reduction in the circulating levels of inflammatory cytokines, indicating that the TGC treatment contributed to a more positive outcome.

Positive effect in children with growth retardation syndrome was reported, following the administration of HT042
(NeuMed Inc. (Seoul, Korea) extract mixture (composed of: A. membranaceus roots, Eleutherococcus senticosus stems, and Phlomis umbrosa roots), twice a day for 24 weeks, who demonstrated to have increased serum levels of insulin-like growth factor binding protein-3 (IGFBP-3) and IGF-1, as well as height and weight gain was observed in all children (Lee et al. 2018). In a randomized study, the co-administration of Astragalus polysaccharide with vinorelbine and cisplatin, in the patients with advanced non-small-cell lung cancer, improved quality of life and the side-effects of chemotherapy, such as appetite loss, pain, vomiting, nausea, and fatigue (Guo et al. 2012).

Immunostimulatory effect was reported as a result of double-blind study, in individuals subjected to treatment with $7.5 \mathrm{ml}$ of an herbal tinctures consisting of Glycyrrhiza glabra, A. membranaceus, and Echinacea purpurea for 7 consecutive days twice a day (via ingestion) that induced the proliferation and activation of human immune cells (Brush et al. 2006). Matkovic et al. (2010) reported the alleviation of seasonal allergic rhinitis symptoms, in patients treated with $80 \mathrm{mg}$ of mineral complex, containing A. membranaceus root extract, for 6 weeks, resulting in positive signals such as decreased rhinorrhea intensity. Improvement of immune function was reported in a clinical trial, with patients with lupus nephritis received cyclophosphamide plus Astragalus (20 ml, intravenous drip infusion) daily for 12 days that, after a month, showed an increase in the red blood cell count and in plasmatic albumin, and reduction in the urine protein content, infection rate, and active clinical symptoms $(P<0.05)$, indicating positive effect (Su et al. 2007).

\section{Conclusions}

Astragalus membranaceus is a widely used medicinal plant containing various natural bioactive compounds with therapeutic potential. For instance, Astragalus polysaccharides are monomeric components extracted from the plant that have been described for potential use in handling a range of diabetic complications (e.g., diabetic neuropathy, diabetic retinopathy, diabetic cardiomyopathy, diabetic foot, and infection). Among its compounds, Astragaloside-IV has been identified as one of the major constituents of its aqueous extract. It is a cycloartane-type triterpene glycoside chemical that has been described to have neuroprotective and hepatoprotective effects and can also be used as anti-cancer and anti-diabetic drug. Its antioxidant properties can also be exploited to improve neurotransmission and further neuroprotection. However, there is still a need for more comprehensive in vitro and in vivo studies, and clinical trials to determine the effective correlation between the chemical composition of this plant and the molecular targets 


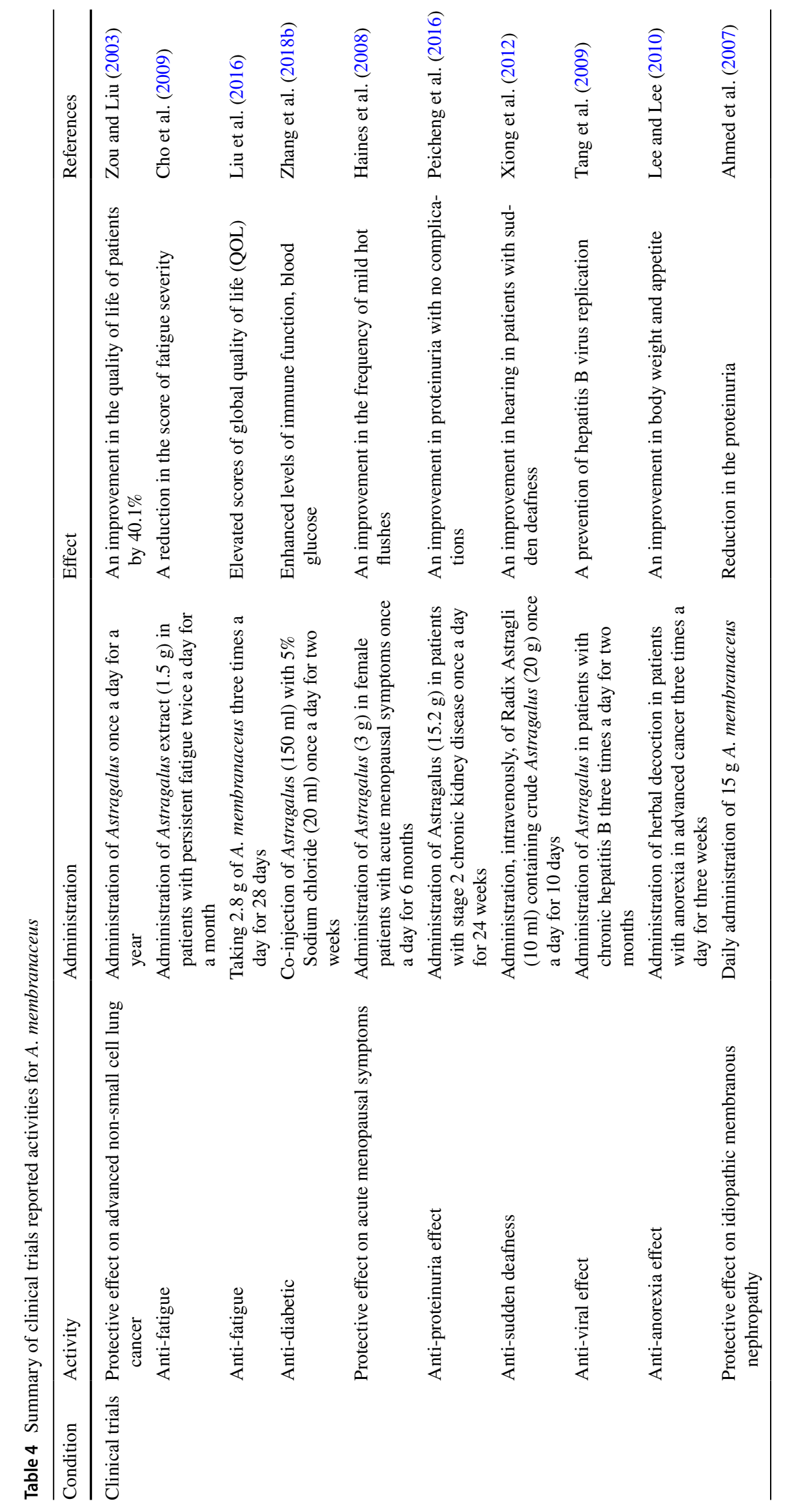


that are responsible for the treatment of diseases that have been claimed, and also to draw definitive conclusions on the effects and consequences of prolonged administration of this plant. Human studies of a small number of health conditions indicate the need to use observational animal experiments for pharmacokinetic characterization. Healthpromoting effects of this plant suggest its added value for potential development of new nutraceuticals as a prophylactic approach before a pharmacological treatment is needed, especially for people who are not eligible for conventional drug therapy. The quality of various chemical compositions derived from A. membranaceus, in particular Astragali Radix, is of great importance due to increasing demand of consumers. Moreover, there are needs to scientifically develop novel technologies to commercialize the plant products, such as pharmaceuticals, foods, health-promoting products, and cosmetics in integrated and multidisciplinary approach (Atanasov et al. 2021; Dwyer et al. 2021).

Author contributions Conceptualization: AD, AN, and AS. Data curation: AD, AN, ML, AMS, and EBS. Writing - original draft preparation: AD, AN, ML, AMS, EBS, and AS. Writing_review and editing: AD, AN, ML, AMS, SBS, PS, EBS, MZ, and AS. Supervision: AS and $\mathrm{AD}$.

Funding Open access funding provided by Università degli Studi di Napoli Federico II within the CRUI-CARE Agreement.

\section{Declarations}

Conflict of interest The authors declare no conflict of interest.

Open Access This article is licensed under a Creative Commons Attribution 4.0 International License, which permits use, sharing, adaptation, distribution and reproduction in any medium or format, as long as you give appropriate credit to the original author(s) and the source, provide a link to the Creative Commons licence, and indicate if changes were made. The images or other third party material in this article are included in the article's Creative Commons licence, unless indicated otherwise in a credit line to the material. If material is not included in the article's Creative Commons licence and your intended use is not permitted by statutory regulation or exceeds the permitted use, you will need to obtain permission directly from the copyright holder. To view a copy of this licence, visit http://creativecommons.org/licenses/by/4.0/.

\section{References}

Adesso S, Russo R, Quaroni A, Marzocco S (2018) Astragalus membranaceus extract attenuates inflammation and oxidative stress in intestinal epithelial cells via NF- $\mathrm{\kappa B}$ activation and Nrf2 response. Intern J Mol Sci 19(3):800

Ahmed MS, Hou SH, Battaglia MC, Picken MM, Leehey DJ (2007) Treatment of idiopathic membranous nephropathy with the herb Astragalus membranaceus. Am J Kidney Dis 50(6):1028-1032
Ali M, Khan T, Fatima K, Ali QUA, Ovais M, Khalil AT, Ullah I, Raza A, Shinwari ZK, Idrees M (2018) Selected hepatoprotective herbal medicines: evidence from ethnomedicinal applications, animal models, and possible mechanism of actions. Phytother Res 32(2):199-215

Atanasov AG, Zotchev SB, Dirsch VM, International Natural Product Sciences Taskforce, Supuran CT (2021) Natural products in drug discovery: advances and opportunities. Nat Rev Drug Discov 20(3):200-216

Attorre F, Pignatti S, Spada F et al (2018) Introduction: vegetation science and the habitats directive: approaches and methodologies of a never-ending story. Rend Fis Acc Lincei 29:233-235

Awad A, Khalil SR, Hendam BM, Abd El-Aziz RM, Metwally MMM, Imam TS (2020) Protective potency of Astragalus polysaccharides against tilmicosin-induced cardiac injury via targeting oxidative stress and cell apoptosis-encoding pathways in rat. Environ Sci Pollut Res Int 27(17):20861-20875

Berezutsky M, Durnova N, Vlasova I (2019) Experimental and clinical studies of mechanisms of the anti-aging effects of chemical compounds in Astragalus membranaceus (review). Adv Geron 32(5):702-710

Bratkov VM, Shkondrov AM, Zdraveva PK, Krasteva IN (2016) Flavonoids from the genus Astragalus: phytochemistry and biological activity. Pharmacogn Rev 10(19):11-32

Brush J, Mendenhall E, Guggenheim A, Chan T, Connelly E, Soumyanath A, Buresh R, Barrett R, Zwickey H (2006) The effect of Echinacea purpurea, Astragalus membranaceus and Glycyrrhiza glabra on CD69 expression and immune cell activation in humans. Phytother Res 20(8):687-695

Cao Y, Shen T, Huang X, Lin Y, Chen B, Pang J, Li G, Wang Q, Zohrabian S, Duan C (2017) Astragalus polysaccharide restores autophagic flux and improves cardiomyocyte function in doxorubicin-induced cardiotoxicity. Oncotarget 8(3):4837-4848

Chan WS, Durairajan SSK, Lu JH, Wang Y, Xie LX, Kum WF, Koo I, Yung KKL, Li M (2009) Neuroprotective effects of Astragaloside IV in 6-hydroxydopamine-treated primary nigral cell culture. Neurochem Intern 55(6):414-422

Chang X, Lu K, Wang L, Lv M, Fu W (2018) Astraglaus polysaccharide protects diabetic cardiomyopathy by activating NRG1/ErbB pathway. Biosci Trends 12(2):149-156

Chao YH, Wu KH, Lin CW, Yang SF, Chao WR, Peng CT, Wu HP (2017) PG2, a botanically derived drug extracted from Astragalus membranaceus, promotes proliferation and immunosuppression of umbilical cord-derived mesenchymal stem cells. J Ethnopharmacol 207:184-191

Chen J, Zhao X, Li X, Wu Y (2015) Calycosin induces apoptosis by the regulation of ER $\beta / \mathrm{miR}-17$ signaling pathway in human colorectal cancer cells. Food and Funct 6(9):3091-3097

Chen SL, Yu H, Luo HM, Wu Q, Li CF, Steinmetz A (2016) Conservation and sustainable use of medicinal plants: problems, progress, and prospects. Chin Med 11(1):37-46

Chen W, Ju J, Yang Y, Wang H, Chen W, Zhao X, Ye H, Zhang Y (2018) Astragalus polysaccharides protect cardiac stem and progenitor cells by the inhibition of oxidative stress-mediated apoptosis in diabetic hearts. Drug Des Devel Ther 12:943-954

Chen Y, Bi L, Luo H, Jiang Y, Chen F, Wang Y, Wei G, Chen W (2019) Water extract of ginseng and Astragalus regulates macrophage polarization and synergistically enhances DDP's anticancer effect. J Ethnopharmacol 232:11-20

Cheng S, Zhang X, Feng Q, Chen J, Shen L, Yu P, Yang L, Chen D, Zhang H, Sun W (2019) Astragaloside IV exerts angiogenesis and cardioprotection after myocardial infarction via regulating PTEN/PI3K/Akt signaling pathway. Life Sci 227:82-93

Cho J, Cho C, Shin J, Son J, Kang W, Son C (2009) Myelophil, an extract mix of Astragali Radix and Salviae Radix, ameliorates 
chronic fatigue: a randomised, double-blind, controlled pilot study. Complement Ther Med 17(3):141-146

Cui Y, Wang Q, Sun R, Guo L, Wang M, Jia J, Xu C, Wu R (2018) Astragalus membranaceus (Fisch.) Bunge repairs intestinal mucosal injury induced by LPS in mice. BMC Complement Altern Med 18(1):1-6

Dai H, Jia G, Lu M, Liang C, Wang Y, Wang H (2017) Astragaloside IV inhibits isoprenaline-induced cardiac fibrosis by targeting the reactive oxygen species/mitogen-activated protein kinase signaling axis. Molecul Med Rep 15(4):1765-1770

Dang X, Jj M, Chen AQ, Li P, Chen L, Liang JR, Xie RM, Zhao Y (2015) The antithrombotic effect of RSNK in blood-stasis model rats. J Ethnopharmacol 173:266-272

Dong Z, Zhao P, Xu M, Zhang C, Guo W, Chen H, Tian J, Wei H, Cao T (2017) Astragaloside IV alleviates heart failure via activating PPAR $\alpha$ to switch glycolysis to fatty acid $\beta$-oxidation. Sci Rep $7(1): 1-15$

Dun C, Liu J, Qiu F, Wu X, Wang Y, Zhao Y, Gu P (2016) Effects of Astragalus polysaccharides on memory impairment in a diabetic rat model. Neuropsychiatr Dis Treat 12:1617-1621

Dwyer JT, Saldanha L, Bailen R, Durazzo A, Le Donne C, Piccinelli R, Andrews K, Pehrsson P, Gusev P, Calvillo A, Connor E, Goshorn J, Sette S, Lucarini M, D’Addezio L, Camilli E, Marletta L, Turrini A (2021) Commentary: an impossible Dream? integrating dietary supplement label databases needs, challenges, next steps. J Food Comp Anal 103882

Fu J, Wang Z, Huang L, Zheng S, Wang D, Chen S, Zhang H, Yang S (2014) Review of the botanical characteristics, phytochemistry, and pharmacology of Astragalus membranaceus (Huangqi). Phytother Res 28(9):1275-1283

Gong L, Chang H, Zhang J, Guo G, Shi J, Xu H (2018) Astragaloside IV protects rat cardiomyocytes from hypoxia-induced injury by down-regulation of miR-23a and miR-92a. Cell Physiol Biochem 49(6):2240-2253

Guarino R, Pignatti S (2010) Diversitas and biodiversity: the roots of a twenty-first century myth. Rend Fis Acc Lincei 21:351-357

Guo L, Bai SP, Zhao L, Wang XH (2012) Astragalus polysaccharide injection integrated with vinorelbine and cisplatin for patients with advanced non-small cell lung cancer: effects on quality of life and survival. Med Oncol 29(3):1656-1662

Guo Z, Xu HY, Xu L, Wang SS, Zhang XM (2016) In vivo and in vitro immunomodulatory and anti-inflammatory effects of total flavonoids of Astragalus. Afr J Tradit Complement Altern Med 13(4):60-73

Guo H, Wan B, Wang J, Zhang J, Yao W, Shen Z (2019) Astragalus saponins inhibit cell growth, aerobic glycolysis and attenuate the inflammatory response in a DSS-induced colitis model. Intern J Mol Med 43(2):1041-1048

Haines C, Lam P, Chung T, Cheng K, Leung P (2008) A randomized, double-blind, placebo-controlled study of the effect of a Chinese herbal medicine preparation (Dang Gui Buxue Tang) on menopausal symptoms in Hong Kong Chinese women. Climacteric 11(3):244-251

He X, Shu J, Xu L, Lu C, Lu A (2012) Inhibitory effect of Astragalus polysaccharides on lipopolysaccharide-induced TNF-a and IL-1 $\beta$ production in THP-1 cells. Molecules 17(3):3155-3164

Ml H, Yuan K, Liang XR, Li H, Li GM (2016) Effect of Astragalus membranaceus (Fisch) Bunge extract on streptozocin-induced diabetic in rats. Trop J Pharm Res 15(7):1465-1471

Izzo AA, Hoon-Kim S, Radhakrishnan R, Williamson EM (2016) A critical approach to evaluating clinical efficacy, adverse events and drug interactions of herbal remedies. Phytother Res 30(5):691-700

Jiang X, Cao X, Huang Y, Chen J, Yao X, Zhao M, Liu Y, Meng J, Li P, Li Z (2015) Effects of treatment with Astragalus membranaceus on function of rat leydig cells. BMC Complement Altern Med 15(1):261

Jiang D, Rasul A, Batool R, Sarfraz I, Hussain G, Mateen Tahir M, Qin T, Selamoglu Z, Ali M, Li J (2019) Potential anticancer properties and mechanisms of action of formononetin. BioMed Res Intern 209:1

Kai Z, Michela P, Antonio P, Annamaria P (2015) Biological active ingredients of traditional Chinese herb Astragalus membranaceus on treatment of diabetes: a systematic review. Med Chem 15(4):315-329

Kim YB, Thwe AA, Li X, Tuan PA, Zhao S, Park CG, Lee JW, Park SU (2014) Accumulation of flavonoids and related gene expressions in different organs of Astragalus membranaceus Bge. Appl Biochem Biotech 173(8):2076-2085

Kim W, Chang MS, Park SK (2016) Astragalus membranaceus augment sperm parameters in male mice associated with cAMPresponsive element modulator and activator of CREM in testis. J Tradit Complement Med 6(3):294-298

Koo HJ, Sohn EH, Kang SC (2013) The optimal combination of the mixture of unripe Rubus coreanus and Astragalus membranaceus in the activation and differentiation of osteoblastic cells. Korean J Plant Res 26(5):658-662

Kumar S, Sephuhle N, Bouic PJ, Rosenkranz B (2018) HPLC/LC-MS guided phytochemical and in vitro screening of Astragalus membranaceus (Fabaceae), and prediction of possible interactions with CYP2B6. J Herb Med 14:35-47

Kwon HJ, Hwang J, Lee SK, Park YD (2013) Astragaloside content in the periderm, cortex, and xylem of Astragalus membranaceus root. J Nat Med 67(4):850-855

Lai W, Cock IE, Cheesman MJ (2018) Interactive antimicrobial profiles of Astragalus membranaceus (Fisch.) Bunge extracts and conventional antibiotics against pathogenic and nonpathogenic gastrointestinal bacteria. Pharmacogn Commun $8(4): 158-164$

Lee JJ, Lee JJ (2010) A phase II study of an herbal decoction that includes Astragali radix for cancer-associated anorexia in patients with advanced cancer. Integr Cancer Ther 9(1):24-31

Lee YS, Han OK, Park CW, Suh SI, Shin SW, Yang CH, Jeon TW, Lee ES, Kim KJ, Kim SH (2003) Immunomodulatory effects of aqueous-extracted Astragali radix in methotrexate-treated mouse spleen cells. J Ethnopharmacol 84(2-3):193-198

Lee KJ, Park MH, Park YH, Lim SH, Kim KH, Kim YG, Ahn YS, Kim HY (2011) Antioxidant activity and nitric oxide production of ethanol extracts from Astragali membranaceus Bunge and A. membranaceus Bunge var mongholicus Hisiao. J Korean Soc Food Sci Nutr 40(12):1793-1796

Lee SM, Jeong S, Kwon HJ, Hong SP (2017) Quantification of isoflavonoids and triterpene saponins in Astragali Radix, the root of Astragalus membranaceus, via reverse-phase high-performance liquid chromatography coupled with integrated pulsed amperometric detection. J Chromatogr B 1070:76-81

Lee D, Lee SH, Song J, Jee HJ, Cha SH, Chang GT (2018) Effects of Astragalus extract mixture HT042 on height growth in children with mild short stature: a multicenter randomized controlled trial. Phytother Res 32(1):49-57

Lee D, Lee DH, Choi S, Lee JS, Jang DS, Kang KS (2019) Identification and isolation of active compounds from Astragalus membranaceus that improve insulin secretion by regulating pancreatic B-Cell metabolism. Biomolecul 9(10):618-628

Lei X, Zhang L, Li Z, Ren J (2018) Astragaloside IV/lncRNA-TUG1/ TRAF5 signaling pathway participates in podocyte apoptosis of diabetic nephropathy rats. Drug Des Devel Ther 12:2785

Li M, Ma RN, Li LH, Qu YZ, Gao GD (2013) Astragaloside IV reduces cerebral edema post-ischemia/reperfusion correlating the suppression of MMP-9 and AQP4. Eur J Pharmacol 715(1-3):189-195 
Li X, Qu L, Dong Y, Han L, Liu E, Fang S, Zhang Y, Wang T (2014a) A review of recent research progress on the Astragalus genus. Molecul 19(11):18850-18880

Li W, Sun YN, Yan XT, Yang SY, Kim S, Lee YM, Koh YS, Kim YH (2014b) Flavonoids from Astragalus membranaceus and their inhibitory effects on LPS-stimulated pro-inflammatory cytokine production in bone marrow-derived dendritic cells. Arch Pharm Res 37(2):186-192

Li H, Nie D, Wang C, Fang J, Li D (2016a) Anti-osteoporosis activity of Astragalus membranaceus Bunge extract in experimental rats. Trop J Pharm Res 15(9):1897-1901

Li J, Huang L, Wang S, Yao Y, Zhang Z (2016b) Astragaloside IV attenuates inflammatory reaction via activating immune function of regulatory T-cells inhibited by HMGB1 in mice. Pharm Biol 54(12):3217-3225

Li J, Xu L, Sang R, Yu Y, Ge B, Zhang X (2018) Immunomodulatory and anti-inflammatory effects of total flavonoids of Astragalus by regulating NF-KB and MAPK signalling pathways in RAW 264.7 macrophages. Die Pharmazie Intern J Pharmaceut Sci 73(10):589-593

Li Q, Xing W, Gong X, Wang Y, Sun H (2019a) Astragalus polysaccharide promotes proliferation and osteogenic differentiation of bone mesenchymal stem cells by down-regulation of microRNA- 152 . Biomed Pharmacother 115:108927

Li ZX, Zhao GD, Xiong W, Linghu KG, Ma QS, San Cheang W, Yu H, Wang Y (2019b) Immunomodulatory effects of a new whole ingredients extract from Astragalus: a combined evaluation on chemistry and pharmacology. Chin Med 14(1):12-21

Li W, Hu X, Wang S, Jiao Z, Sun T, Liu T, Song K (2020) Characterization and anti-tumor bioactivity of Astragalus polysaccharides by immunomodulation. Int J Biol Macromol 145:985-997

Liang Y, Zhang Q, Zhang L, Wang R, Xu X, Hu X (2019) Astragalus membranaceus treatment protects Raw264.7 cells from influenza virus by regulating G1 phase and the TLR3-mediated signaling pathway. Evid Complement Altern Med

Lim C, Lee B, Lim S, Lee SE, Cho S (2019) Astragali radix reduces ischemia-induced brain injury by inhibiting edema and expression of Aquaporin-4 in mice. Pharmacogn Mag 15(61):335-341

Lin M, Mao ZJ (2020) lncRNA-mRNA competing endogenous RNA network in IR-hepG2 cells ameliorated by APBBR decreasing ROS levels: a systematic analysis. PeerJ 8:e8604

Liu CH, Tsai CH, Li TC, Yang YW, Huang WS, Lu MK, Tseng CH, Huang HC, Chen KF, Hsu TS (2016) Effects of the traditional Chinese herb Astragalus membranaceus in patients with poststroke fatigue: a double-blind, randomized, controlled preliminary study. J Ethnopharmacol 194:954-962

Liu XY, Xu L, Wang Y, Li JX, Zhang Y, Zhang C, Wang SS, Zhang XM (2017) Protective effects of total flavonoids of Astragalus against adjuvant-induced arthritis in rats by regulating OPG/ RANKL/NF-KB pathway. Intern Immunopharmacol 44:105-114

Liu Y, Liu J, Wu KX, Guo XR, Tang ZH (2018) A rapid method for sensitive profiling of bioactive triterpene and flavonoid from Astragalus mongholicus and Astragalus membranaceus by ultrapressure liquid chromatography with tandem mass spectrometry. J Chromatog B 1085:110-118

Lu W, Li S, Guo W, Chen L, Li Y (2015) Effects of Astragaloside IV on diabetic nephropathy in rats. Genet Mol Res 14(2):5427-5434

Lu M, Tang F, Li X, Zhang J, He X, Mei M, Hou X, Yang J, Gao J, Wang H (2016) Astragaloside IV attenuates pressure overload-induced cardiac hypertrophy by regulating PGC- $1 \alpha$ signaling mediated energy biosynthesis. Intern J Clin Exper Med 9(3):5666-5676

Mao S, Ouyang W, Zhou Y, Zeng R, Zhao X, Chen Q, Zhang M, Hinek A (2020) Addition of Chinese herbal remedy, Tongguan Capsules, to the standard treatment in patients with myocardial infarction improve the ventricular reperfusion and remodeling: proteomic analysis of possible signaling pathways. J Ethnopharmacol 257:112794

Maresca M, Micheli L, Cinci L, Bilia AR, Ghelardini C, Di Cesare ML (2017) Pain relieving and protective effects of Astragalus hydroalcoholic extract in rat arthritis models. J Pharm Pharmacol 69(12): $1858-1870$

Matkovic Z, Zivkovic V, Korica M, Plavec D, Pecanic S, Tudoric N (2010) Efficacy and safety of Astragalus membranaceus in the treatment of patients with seasonal allergic rhinitis. Phytother Res 24(2):175-181

Mohibbullah M, Bashir KMI, Kim SK, Hong YK, Kim A, Ku SK, Choi JS (2019) Protective effects of a mixed plant extracts derived from Astragalus membranaceus and Laminaria japonica on PTU-induced hypothyroidism and liver damages. J Food Biochem 43(7):e12853

Orkhon B, Kobayashi K, Javzan B, Sasaki K (2018) Astragalus root induces ovarian $\beta$-oxidation and suppresses estrogen-dependent uterine proliferation. Mol Med Rep 18(6):5198-5206

Ou L, Wei P, Li M, Gao F (2019) Inhibitory effect of Astragalus polysaccharide on osteoporosis in ovariectomized rats by regulating FoxO3a/Wnt signaling pathway. Acta Cir Bras 34(5):e201900502

Park HJ, Park SH (2018) Induction of apoptosis by Ethyl Acetate Fraction of Astragalus membranaceus in human non-small cell lung cancer cells:-apoptosis induction by Astragalus membranaceus. J Pharmacopunct 21(4):268

Peicheng S, Xuejun Y, Liqun H (2016) Effect of Astragali and Angelica particle on proteinuria in Chinese patients with primary glomerulonephritis. J Trad Chin Med 36(3):299-306

Pignatti S (2013) A discussion on the foundations of environmental ethics. Rend Fis Acc Lincei 24:89-94. https://doi.org/10.1007/ s12210-013-0226-4

Pignatti S, Cipriani M (2010) The diversity of plants in a text from the seventeenth century. Rend Fis Acc Lincei. https://doi.org/10. 1007/s12210-010-0105-1

Qin L, Tan HL, Wang YG, Xu CY, Feng J, Li M, Dou YQ (2018) Astragalus membranaceus and salvia miltiorrhiza ameliorate lipopolysaccharide-induced acute lung injury in rats by regulating the toll-like receptor 4/nuclear factor-Kappa B signaling pathway. Evid Complement Altern Med

Qiu LH, Zhang BQ, Lian MJ, Xie XJ, Chen P (2017) Vascular protective effects of Astragalus membranaceus and its main constituents in rats with chronic hyperhomocysteinemia. Exper Thera Med 14(3):2401-2407

Rahman M, Kim HK, Kim SE, Kim MJ, Kim DH, Lee HS (2018) Chondroprotective effects of a standardized extract (KBHJP-040) from Kalopanax pictus, Hericium erinaceus, and Astragalus membranaceus in experimentally induced in vitro and in vivo osteoarthritis models. Nutr 10(3):356

Ren Q, Zhao S, Ren C, Ma Z (2018) Astragalus polysaccharide alleviates LPS-induced inflammation injury by regulating miR-127 in H9c2 cardiomyoblasts. Intern J Immunopathol Pharmacol 31:205873841875918

Shahrajabian MH, Sun W, Cheng Q (2019) Astragalus, an ancient medicinal root in traditional Chinese medicine, a gift from silk road. Intern J Agricul Biol Sci 3(06):27-38

Song J, Chen Y, He D, Tan W, Lv F, Liang B, Xia T, Li J (2020) Astragalus polysaccharide promotes adriamycin-induced apoptosis in gastric cancer cells. Cancer Manag Res 12:2405-2414

Souto EB, Sampaio AC, Campos JR, Martins-Gomes C, Aires A, Silva AM (2019) Polyphenols for skin cancer: chemical properties, structure-related mechanisms of action and new delivery systems. In: Rahman A (ed) Studies in natural products chemistry, vol 63. Elsevier, Amsterdam, pp 21-42 
Su L, Mao J, Gu J (2007) Effect of intravenous drip infusion of cyclophosphamide with high-dose Astragalus injection in treating lupus nephritis. Zhong Xi Yi Jie He Xue Bao 5(3):272-275

Sun S, Yang S, Dai M, Jia X, Wang Q, Zhang Z, Mao Y (2017) The effect of Astragalus polysaccharides on attenuation of diabetic cardiomyopathy through inhibiting the extrinsic and intrinsic apoptotic pathways in high glucose-stimulated $\mathrm{H} 9 \mathrm{C} 2$ cells. BMC Complement Altern Med 17(1):310

Sun S, Yang S, An N, Wang G, Xu Q, Liu J, Mao Y (2019) Astragalus polysaccharides inhibits cardiomyocyte apoptosis during diabetic cardiomyopathy via the endoplasmic reticulum stress pathway. J Ethnopharmacol 238:111857

Tang L, Sheng J, Xu C, Liu K (2009) Clinical and experimental effectiveness of Astragali compound in the treatment of chronic viral hepatitis B. J Intern Med Res 37(3):662-667

Tseng A, Yang CH, Chen CH, Chen CH, Hsu SL, Lee MH, Lee HC, Su LJ (2016) An in vivo molecular response analysis of colorectal cancer treated with Astragalus membranaceus extract. Oncol Rep 35(2):659-668

Van Eck NJ (2011). Methodological advances in bibliometric mapping of science. PhD thesis, Erasmus University Rotterdam

Van Eck NJ, Waltman L (2009) Software survey: VOSviewer, a computer program for bibliometric mapping. Scientometrics 84:523538. https://doi.org/10.1007/s11192-009-0146-3

Van Eck NJ, Waltman L (2010) Software survey: VOSviewer, a computer program for bibliometric mapping. Scientometrics 84(2):523-538

Van Eck NJ, Waltman L (2011) Text mining and visualization using VOSviewer. ISSI Newslett 7:50-54

VOSviewer software (version 1.6.16,). www.vosviewer.com

Waltman L, Van Eck NJ, Noyons EC (2010) A unified approach to mapping and clustering of bibliometric networks. J Informetr 4:629-635

Wang Y, Ba Y (2015) Studies on the chemical constituents of Radix astragali and their inhibitory effect on HepG2 proliferation. Biomed Res 26(2):393-398

Wang Y, Ren T, Zheng L, Chen H, Ko JK, Auyeung KK (2016) Astragalus saponins inhibits lipopolysaccharide-induced inflammation in mouse macrophages. Am J Chin Med 44(03):579-593

Wang T, Zhou X, Zou W, Zhang P, Wang J, Li H, Wei S, Li K, Gao J, Li Y (2018a) Synergistic effects of Ginseng CA Mey and Astragalus membranaceus (Fisch.) Bunge on activating mice splenic lymphocytes detected by microcalorimetry and the underlying mechanisms predicted by in silico network analysis. J Therm Anal Calorimetr 132(3):1933-1942

Wang Y, Li J, Xuan L, Liu Y, Ge H, Gu J, Wei C, Zhao M (2018b) Astragalus Root dry extract restores connexin 43 expression by targeting miR-1 in viral myocarditis. Phytomed 46:32-38

Wang F, Chen S, Deng L, Chen L, Huang Y, Tian M, Li C, Zhou X (2019) Protective effects of Astragaloside IV against LPSinduced endometritis in mice through inhibiting activation of the NF-אB, p38 and JNK signaling pathways. Molecules 24:373

Wang E, Wang L, Ding R, Zhai M, Ge R, Zhou P, Wang T, Fang H, Wang J, Huang J (2020) Astragaloside IV acts through multiscale mechanisms to effectively reduce diabetic nephropathy. Pharmacol Res 157:104831

Wei W, Xiao HT, Bao WR, Ma DL, Leung CH, Han XQ, Ko CH, Bik-San Lau C, Chun-Kwok W, Fung KP (2016) TLR-4 may mediate signaling pathways of Astragalus polysaccharide RAP induced cytokine expression of RAW264. 7 cells. J Ethnopharmacol 179:243-252

Wei Y, Wu Y, Feng K, Zhao Y, Tao R, Xu H, Tang Y (2020) Astragaloside IV inhibits cardiac fibrosis via miR-135a-TRPM7-TGF- $\beta$ / Smads pathway. J Ethnopharmacol 249:112404
Wen D, Tan RZ, Zhao CY, Li JC, Zhong X, Diao H, Lin X, Duan DD, Fan JM, Xie XS (2020) Astragalus mongholicus Bunge and Panax notoginseng (Burkill) FH chen formula for renal injury in diabetic nephropathy-in vivo and in vitro evidence for autophagy regulation. Front Pharmacol 11

Wu J, Ke X, Ma N, Wang W, Fu W, Zhang H, Zhao M, Gao X, Hao X, Zhang Z (2016) Formononetin, an active compound of Astragalus membranaceus (Fisch) Bunge, inhibits hypoxia-induced retinal neovascularization via the HIF-1 $\alpha /$ VEGF signaling pathway. Drug Des Dev Ther 10:3071

Wu J, Yu J, Wang J, Zhang C, Shang K, Yao X, Cao B (2018) Astragalus polysaccharide enhanced antitumor effects of apatinib in gastric cancer AGS cells by inhibiting AKT signalling pathway. Biomed Pharmacother 100:176-183

Xiong M, He Q, Lai H, Huang W, Wang L, Yang C (2012) Radix astragali injection enhances recovery from sudden deafness. Am J Otolaryngol 33(5):523-527

Yang P, Zhou Y, Xia Q, Yao L, Chang X (2019) Astragaloside IV regulates the PI3K/Akt/HO-1 signaling pathway and inhibits $\mathrm{H} 9 \mathrm{c} 2$ cardiomyocyte injury induced by hypoxia-reoxygenation. Biol Pharm Bull 42(5):721-727

Yi YE, Li SY, Nie YN, Jia DX, Zhang Zh, Wang YF, Wang Q (2016) Effect of Astragalus injection on renal tubular epithelial transdifferentiation in type 2 diabetic mice. BMC Complement Altern Med 16(1):1-9

Yin X, Zhang Y, Wu H, Zhu X, Zheng X, Jiang S, Zhuo H, Shen J, Li L, Qiu J (2004) Protective effects of Astragalus saponin I on early stage of diabetic nephropathy in rats. J Pharmacol Sci 95(2):256-266

Yin F, Zhou H, Fang Y, Li C, He Y, Yu L, Wan H, Yang J (2020) Astragaloside IV alleviates ischemia reperfusion-induced apoptosis by inhibiting the activation of key factors in death receptor pathway and mitochondrial pathway. J Ethnopharmacol 248:112319

Yu J, Zhang X, Zhang Y (2017) Astragaloside attenuates myocardial injury in a rat model of acute myocardial infarction by upregulating hypoxia inducible factor- $1 \alpha$ and Notch1/Jagged1 signaling. Mol Med Rep 15(6):4015-4020

Yu J, Hai-Yu J, Liu AJ (2018) Alcohol-soluble polysaccharide from Astragalus membranaceus: preparation, characteristics and antitumor activity. Intern J Bio Macromol 118:2057-2064

Yue R, Li X, Chen B, Zhao J, He W, Yuan H, Yuan X, Gao N, Wu G, Jin H (2015) Astragaloside IV attenuates glutamate-induced neurotoxicity in PC12 cells through Raf-MEK-ERK pathway. PLoS ONE 10(5): $\mathrm{e} 0126603$

Zhai R, Jian G, Chen T, Xie L, Xue R, Gao C, Wang N, Xu Y, Gui D (2019) Astragalus membranaceus and Panax notoginseng, the novel renoprotective compound, synergistically protect against podocyte injury in streptozotocin-induced diabetic rats. J Diabetes Res 1:1-14

Zhang WD, Chen H, Zhang C, Liu RH, Li HL, Chen HZ (2006) Astragaloside IV from Astragalus membranaceus shows cardioprotection during myocardial ischemia in vivo and in vitro. Planta Med 72(01):4-8

Zhang LJ, Liu HK, Hsiao PC, Kuo LMY, Lee IJ, Wu TS, Chiou WF, Kuo YH (2011) New isoflavonoid glycosides and related constituents from astragali radix (Astragalus membranaceus) and their inhibitory activity on nitric oxide production. J Agric Food Chem 59(4):1131-1137

Zhang G, Zhou SM, Zheng SJ, Liu FY, Gao YQ (2015) Astragalus on the anti-fatigue effect in hypoxic mice. Intern J Clin Exp Med $8(8): 14030$ 
Zhang J, Liu L, Wang J, Ren B, Zhang L, Li W (2018a) Formononetin, an isoflavone from Astragalus membranaceus inhibits proliferation and metastasis of ovarian cancer cells. J Ethnopharmacol 221:91-99

Zhang X, Zhang Y, Sun Z, Wang L (2018b) Clinical efficacy of Astragalus injection combined with anti-tuberculosis drugs on children with pulmonary tuberculosis complicated with type II diabetes and its influence on serum levels of LEP and APN. Pharm Bioprocess 6(2):30-36

Zhang CH, Yang X, Wei JR, Chen NM, Xu JP, Bi YQ, Yang M, Gong X, Li ZY, Ren K, Han QH, Zhang L, Li X, Ji MY, Wang CC, Li M (2019) Ethnopharmacology phytochemistry pharmacology toxicology and clinical applications of radix astragali. Chin J Integr Med. https://doi.org/10.1007/s11655-019-3032-8 (PMID 31502185)

Zhang J, Wu C, Gao L, Du G, Qin X (2020a) Astragaloside IV derived from Astragalus membranaceus: a research review on the pharmacological effects. Adv Pharmacol 87:89-112

Zhang Z, Auyeung KKW, Sze SCW, Zhang S, Yung KKL, Ko JKS (2020b) The dual roles of calycosin in growth inhibition and metastatic progression during pancreatic cancer development: a "TGF- $\beta$ paradox." Phytomedicine 68:153176

Zhao W, Chen L, Cui N, Ji X, Jiang H, Deng T, Wang S (2019) Polysaccharides from radix astragali exert immunostimulatory effects to attenuate the dampness stagnancy due to spleen deficiency syndrome. Pharmacogn Mag 15(63):500-506

Zhou X, Sun X, Gong X, Yang Y, Chen C, Shan G, Yao Q (2017) Astragaloside IV from Astragalus membranaceus ameliorates renal interstitial fibrosis by inhibiting inflammation via TLR4/ NF- $\mathrm{\kappa B}$ in vivo and in vitro. Intern Immunopharmacol 42:18-24

Zhou R, Chen H, Chen J, Chen X, Wen Y, Xu L (2018) Extract from Astragalus membranaceus inhibit breast cancer cells proliferation via PI3K/AKT/mTOR signaling pathway. BMC Complement Altern Med 18(1):83-90

Zhu Y, Qian X, Li J, Lin X, Luo J, Huang J, Jin Z (2019) Astragaloside-IV protects $\mathrm{H} 9 \mathrm{C} 2(2-1)$ cardiomyocytes from high glucoseinduced injury via miR-34a-mediated autophagy pathway. Art Cells Nanomed Biotechnol 47(1):4172-4181

Zou Y, Liu X (2003) Effect of Astragalus injection combined with chemotherapy on quality of life in patients with advanced nonsmall cell lung cancer. Zhongguo Zhong Xi Yi Jie He Za Zhi Zhongguo Zhongxiyi Jiehe Zazhi 23(10):733-735

Publisher's Note Springer Nature remains neutral with regard to jurisdictional claims in published maps and institutional affiliations.

\section{Authors and Affiliations}

\section{Alessandra Durazzo ${ }^{1}$ Amirhossein Nazhand ${ }^{2}$. Massimo Lucarini ${ }^{1} \cdot$ Amelia M. Silva $^{3,4}$. Selma B. Souto ${ }^{5}$ Fabrizia Guerra ${ }^{6}$. Patricia Severino $0^{7,8,9} \cdot$ Massimo Zaccardelli $^{10} \cdot$ Eliana B. Souto ${ }^{11,12} \cdot$ Antonello Santini $^{6}$ (B)}

Antonello Santini

asantini@unina.it

Alessandra Durazzo

alessandra.durazzo@crea.gov.it

Amirhossein Nazhand

nazhand.ah@gmail.com

Massimo Lucarini

massimo.lucarini@crea.gov.it

Amelia M. Silva

amsilva@utad.pt

Selma B. Souto

sbsouto.md@gmail.com

Fabrizia Guerra

fabrizia.guerra@unina.it

Patricia Severino

pattypharma@gmail.com

Massimo Zaccardelli

massimo.zaccardelli@crea.gov.it

Eliana B. Souto

souto.eliana@gmail.com

1 CREA-Research Centre for Food and Nutrition, Via Ardeatina 546, 00178 Rome, Italy

2 Department of Biotechnology, Sari Agricultural Science and Natural Resource University, Sari 48181 68984, 9th km of Farah Abad Road, Mazandaran, Iran
3 School of Biology and Environment, University of Trás-os-Montes e Alto Douro (UTAD), Quinta de Prados, 5001-801 Vila Real, Portugal

4 Centre for Research and Technology of Agro-Environmental and Biological Sciences (CITAB), University of Trás-os-Montes e Alto Douro (UTAD), Vila Real, Portugal

5 Department of Endocrinology, Hospital de São João, Alameda Prof. Hernâni Monteiro, 4200-319 Porto, Portugal

6 Department of Pharmacy, University of Napoli Federico II, Via D. Montesano 49, 80131 Naples, Italy

7 Industrial Biotechnology Program, University of Tiradentes (UNIT), Av. Murilo Dantas 300, Aracaju 49032-490, Brazil

8 Tiradentes Institute, $150 \mathrm{Mt}$ Vernon St, Dorchester, MA 02125, USA

9 Laboratory of Nanotechnology and Nanomedicine (LNMED), Institute of Technology and Research (ITP), Av. Murilo Dantas, 300, Aracaju 49010-390, Brazil

10 CREA-Research Centre for Vegetable and Ornamental Crops, Via Cavalleggeri 25, 84098 Pontecagnano, Salerno, Italy

11 Department of Pharmaceutical Technology, Faculty of Pharmacy, University of Coimbra, Pólo das Ciências da Saúde, Azinhaga de Santa Comba, 3000-548 Coimbra, Portugal

12 CEB-Centre of Biological Engineering, University of Minho, Campus de Gualtar, 4710-057 Braga, Portugal 